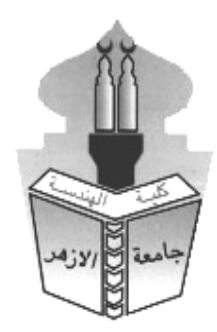

\title{
MECHANICAL BEHAVIOR OF HIGH STRENGTH CONCRETE INCORPORATING SILICA FUME AND AMORPHOUS NANO-SILICA AT DIFFERENT CEMENT CONTENTS
}

\author{
S. S. E. Ahmad, H. S. Khalil, A.H. Atia and A. Fawzy \\ Mat.Dept., Faculty of Engineering Zagazig University, Egypt
}

\begin{abstract}
In this paper, an experimental investigation on the use of silica fume and amorphous Nano silica on compressive and tensile strength of HSC was done at different cement contents. The percent of Silica fume and Nano silica were $10 \%$ and $1 \%$ respectively. Three cement contents, namely, $500 \mathrm{~kg} / \mathrm{m}^{3}, 600 \mathrm{~kg} / \mathrm{m}^{3}$ and $700 \mathrm{~kg} / \mathrm{m}^{3}$ were used. All tests were performed at 28 and 56 days. Silica fume and amorphous Nano-silica are used as partial replacement of cement. Further investigation was carried out by combined replacement of silica fume (10\%) and Nano silica (1\%) of cement in the same mix. Compressive and split tensile strength of these mixes were measured and compared with the control concrete specimens. The experimental test results showed that concrete prepared with (1\%) nano silica showed a good comparable strength (either compressive or splitting tensile) than the other two concrete mixes of $10 \%$ silica fume or combined silica+nano concrete. The test results showed also that there is a decrease in ratio of tensile to compressive strength as cement content increased for both $10 \%$ silica fume concrete and $1 \%$ nano silica concrete due to the more increase in compressive strength gain.
\end{abstract}

\section{Keywords: High Strength Concrete, Silica Fume, Nano Silica, Silica Fume,} Replacement, Compressive Strength, Tensile Strength.

\section{INTRODUCTION}

High Strength Concrete, HSC; offer many advantages and it has been gradually replacing normal strength concrete due to its improved mechanical characteristics. Silica fume is one of the most important components in HSC micro-structure quality improvement, therefore extensive research is directed towards the performance of pozzolana concrete in recent years. Moreover, Nano silica is, also, appears to be one of the attractive cement and silica fume substitution alternatives for many researchers in order to study the effects of its incorporation on fresh and hardened concrete properties.

The construction industry uses concrete to a very large extent, cement is one of the important components of concrete, and the production of high strength concrete is more important and increasing day-by-day and the requirement high cement content. High strength concrete with high strength and durability properties offer many advantages and they have been gradually replacing normal strength concrete due to their improved mechanical characteristics and low permeability [1].Portland cement production is one of the major reasons for $\mathrm{CO}_{2}$ emissions into atmosphere as required to generate electricity during the cement manufacturing process. Hence to reduce the consumption of cement, the application pozzolana materials is increasing in the form of a partial replacement of cement for concrete preparation. The use of pozzolana's for making concrete is considered efficient, and it allows the reduction of the cement consumption while improving the strength and durability's of concrete. 
Silica fume is one of the most important components in concrete micro- structure quality improvement, Therefore extensive research is directed towards the performance of pozzolana concrete in recent years when is added to cement it acts as a filler to fill the gaps between cement particles resulting in finer pore structure. Also more C-S-H gel can be formed in silica fume concrete due to the reaction that occurs between the silica and the $\mathrm{Ca}$ $(\mathrm{OH})_{2}$ in hydrating cement.

Nano silica appears to be one of the attractive cement substitution alternatives for many researchers, several researchers have studied the effects of its incorporation on fresh and hardened concrete properties, Susheel etal [2] studied the effect of incorporating constant partial replacement of $(5 \%)$ Silica fume in addition to variable partial replacement of Nano silica from $(0 \%)$ to $(4 \%)$ of $(1 \%)$ Nano on concrete properties (cement is replaced by silica fume and Nano silica and added together in one concrete mixes) [4]. He found that the highest compressive strength with $(3 \%)$ of Nano silica and $(5 \%)$ of silica fume.Also in case of split tensile strength,the highest strength with (2\%) of Nano silica and (5\%) silica fume appears to be the optimum in present condition for split tensile strength.

Quing etal [3] reported that Nano silica improved the bond strength of paste- aggregate interface, additional studies have also concluded that pozzolanic activity of Nano silica was much greater than that of silica fume, Li H etal [4] suggested that Nano silica was valuable for enhancing abrasion resistance of pavement, Lin K.L. etal [5] reported that Nano silica particles could potentially found that when Nano silica particles uniformly dispersed in cement paste they will accelerate cement hydration due to their high activity, owing to the unique properties of Nano silica it seems that it has a potential to be utilized in production of high strength concrete, Hence more assessment are necessary to ensure usage possibility of Nano silica particles were incorporated into ordinary cement and compressive strength, flexural and behavior.

\section{MATERIALS AND METHODS:}

The details descriptions of materials used through this investigation, particularly cement, silica fume, Nano silica. Silica fume, aggregate, water and chemical admixtures were chosen from the available materials in Egypt.

Cement for this study is manufactured in Egypt by MBSC is ordinary Portland cement type I of 52.5 grade. The specific gravity of the cement is 3.15. Fine aggregate, locally available river sand (zone-II) confirming to is specification with fineness modulus of 2.95. Coarse aggregate, machine crushed aggregate obtained from the local quarry with nominal size of coarse (NMS) aggregate adopted in the present investigation passing sieve $10 \mathrm{~mm}$ and retained on sieve $5 \mathrm{~mm}$ with a specific gravity of 2.64. Silica fume used in this experiment contained $93.9 \% \mathrm{SiO}_{2}$ with average particle size of $7.38 \mathrm{~nm}$. Nano silica, amorphous pozzolanic material its reduced size of its spherical particles equal $19.4 \mathrm{~nm}$. The chemical composition of cement, silica fume and Nano silica fume are given in table (1).

Table (1) XRD chemical composition percent of cement, silica fume and nano silica.

\begin{tabular}{|c|c|c|c|c|c|c|c|}
\hline & $\mathbf{S i O}_{\mathbf{2}}$ & $\mathrm{Al}_{\mathbf{2}} \mathbf{O}_{\mathbf{3}}$ & $\mathbf{F e}_{\mathbf{2}} \mathbf{O}_{\mathbf{3}}$ & $\mathbf{C a O}$ & $\mathbf{M g O}$ & $\mathbf{S O}_{3}$ & L.O.I \\
\hline Cement & 21.5 & 3.68 & 2.76 & 61.5 & 4.8 & - & 1.35 \\
\hline Silica fume & 93.9 & 0.42 & 0.71 & 0.29 & 0.93 & 0.26 & 2.16 \\
\hline Nano silica & 90.90 & 0.17 & 0.07 & 0.09 & 0.01 & 0.19 & 8.31 \\
\hline
\end{tabular}

Water, is free from acids, organic matter suspended solids and impurities which when present can adversely affect the strength of concrete

\section{Concrete mix proportion:}

1) M500, M600 and M700 cement content of concrete was designed as, the quantities of mix designed is shown in tables $(2,3$ and 4$)$

2) The W/C water cement ratio was 0.32 
3) The mix of Nano silica was sonication with the ultra-sonic cleaner for 15 minute at 37 temperature

4) Concrete test specimens consists of $10 \mathrm{~mm} * 10 \mathrm{~mm} * 10 \mathrm{~mm}$ cubes and cylinder of 10 $\mathrm{mm}$ diameter and $200 \mathrm{~mm}$ height.

5) Concrete cubes were tested at 28 and 56 days of curing to obtain the compressive strength of concrete cylindrical specimens were tested at the 28 and 56 days to obtain the split tensile strength of concrete.

6) The slump test for (5 to 10 ) $\mathrm{Cm}$ by change the ratio Galineme in mixes. The galineme was master gleniumrmc 315 .

Table (2) Mix design for cement content $\left(500 \mathrm{~kg} / \mathrm{m}^{3}\right)$

\begin{tabular}{|c|c|c|c|c|c|c|}
\hline Mix & $\mathbf{C}, \mathbf{~ k g} / \mathbf{m}^{\mathbf{3}}$ & $\mathbf{S . F}, \mathbf{~ k g} / \mathbf{m}^{\mathbf{3}}$ & $\mathbf{N . S ~} \mathbf{~ k g} / \mathbf{m}^{\mathbf{3}}$ & $\mathbf{w} / \mathbf{c}$ & Galineme $\%$ & NMS \\
\hline $\mathrm{C}$ & 500 & - & - & 0.32 & $1.50 \%$ & $10 \mathrm{~mm}$ \\
\hline $\mathrm{Cs}$ & 450 & 50 & - & 0.32 & $1.50 \%$ & $10 \mathrm{~mm}$ \\
\hline $\mathrm{CN}$ & 495 & - & $5(1 \%)$ & 0.32 & $1.50 \%$ & $10 \mathrm{~mm}$ \\
\hline $\mathrm{CSN}$ & 445 & 50 & 5 & 0.32 & $1.50 \%$ & $10 \mathrm{~mm}$ \\
\hline
\end{tabular}

Table (3) Mix design for cement content $\left(600 \mathrm{~kg} / \mathrm{m}^{3}\right)$

\begin{tabular}{|c|c|c|c|c|c|c|}
\hline Mix & $\mathbf{C}, \mathbf{~ k g} / \mathbf{m}^{\mathbf{3}}$ & $\mathbf{S . F}, \mathbf{~ k g} / \mathbf{m}^{\mathbf{3}}$ & $\mathbf{N} . \mathbf{S ~ k g} / \mathbf{m}^{\mathbf{3}}$ & $\mathbf{w} / \mathbf{c}$ & Galineme $\%$ & $\mathbf{N M S}$ \\
\hline $\mathrm{C}$ & 600 & - & - & 0.32 & $2 \%$ & $10 \mathrm{~mm}$ \\
\hline $\mathrm{Cs}$ & 540 & 60 & - & 0.32 & $2 \%$ & $10 \mathrm{~mm}$ \\
\hline $\mathrm{CN}$ & 594 & - & 6 & 0.32 & $2 \%$ & $10 \mathrm{~mm}$ \\
\hline $\mathrm{CSN}$ & 534 & 60 & 6 & 0.32 & $2 \%$ & $10 \mathrm{~mm}$ \\
\hline
\end{tabular}

Table (4) Mix design for cement content $\left(700 \mathrm{~kg} / \mathrm{m}^{3}\right)$

\begin{tabular}{|c|c|c|c|c|c|c|}
\hline $\mathbf{M i x}$ & $\mathbf{C}, \mathbf{~ k g} / \mathbf{m}^{\mathbf{3}}$ & $\mathbf{S . F}, \mathbf{~ k g} / \mathbf{m}^{\mathbf{3}}$ & $\mathbf{N} . \mathbf{S ~ k g} / \mathbf{m}^{3}$ & $\mathbf{w} / \mathbf{c}$ & Galineme $\%$ & NMS \\
\hline $\mathrm{C}$ & 700 & - & - & 0.32 & $2 \%$ & $10 \mathrm{~mm}$ \\
\hline $\mathrm{Cs}$ & 630 & 70 & - & 0.32 & $2 \%$ & $10 \mathrm{~mm}$ \\
\hline $\mathrm{CN}$ & 693 & - & 7 & 0.32 & $2 \%$ & $10 \mathrm{~mm}$ \\
\hline $\mathrm{CSN}$ & 623 & 70 & 7 & 0.32 & $2 \%$ & $10 \mathrm{~mm}$ \\
\hline
\end{tabular}

\section{RESULTS, ANALYSIS AND DISCUSSION \\ A- Compressive Strength}

Table (5) gives the results of compressive strength, $\sigma_{c}$, for all the tested specimens at 28 and 56 days. Figure 1 shows the behavior of 28 days $\sigma_{c}$ against cement content for all mixes. From the data in this figure one can notice that the compressive strength of all mixes increases as the cement content increase from $500 \mathrm{~kg} / \mathrm{m}^{3}$ to $700 \mathrm{~kg} / \mathrm{m}^{3}$. The rate of increasing in compressive strength with cement content is approximately equals for cement and cement+ Nano mixes. While the mixes of cement + silica and cement + Nano + silica showed a higher rate of increasing especially from 500 to $700 \mathrm{~kg} / \mathrm{m}^{3}$. Moreover, the incorporating of silica fume in mix gives more benefit for compressive strength, where $\sigma_{\mathrm{c}}$ of cement + silica mix is higher than other mixes.

As shown from the results, the presence of $1 \%$ Nano silica increase the compressive strength of the test specimen at 28 days by $17 \%, 14 \%$ and $15 \%$ for cement contents of 500, 600 and $700 \mathrm{~kg} / \mathrm{m}^{3}$ respectively. This can be attributed to the effect of pozzolanic reaction of the Nano silica material. The Nano silica reacted with the free calcium hydroxide resulting from the hydration of cement, and the resulting compounds filled the inner pores leading to lower permeability and higher ability to resist loads (physical effect). In addition, the resulting compounds are active due calcium silicate hydrates, which are actually a cementation material increasing the ability to resist high loads (chemical effect). 
Table (5) Compressive strength results

\begin{tabular}{|c|c|c|c|c|c|c|c|c|c|c|c|c|}
\hline \multirow[b]{3}{*}{ Mix } & \multicolumn{4}{|c|}{ C C $500 \mathrm{~kg} / \mathrm{m}^{3}$} & \multicolumn{4}{|c|}{ C C $600 \mathrm{~kg} / \mathrm{m}^{3}$} & \multicolumn{4}{|c|}{ C C $700 \mathrm{~kg} / \mathrm{m}^{3}$} \\
\hline & \multicolumn{2}{|c|}{28 day } & \multicolumn{2}{|c|}{56 day } & \multicolumn{2}{|c|}{28 day } & \multicolumn{2}{|c|}{56 day } & \multicolumn{2}{|c|}{28 day } & \multicolumn{2}{|c|}{56 day } \\
\hline & $\begin{array}{c}\sigma_{\mathrm{c}} \\
\mathbf{M P a}\end{array}$ & Relative & $\begin{array}{c}\sigma_{\mathrm{c}} \\
\mathbf{M P a}\end{array}$ & Relative & $\begin{array}{c}\sigma_{\mathrm{c}} \\
\mathbf{M P a}\end{array}$ & Relative & $\begin{array}{c}\sigma_{\mathrm{c}} \\
\mathbf{M P a}\end{array}$ & Relative & $\begin{array}{c}\sigma_{\mathrm{c}} \\
\mathbf{M P a}\end{array}$ & Relative & $\begin{array}{c}\sigma_{\mathrm{c}} \\
\mathbf{M P a}\end{array}$ & Relative \\
\hline Cement (C) & 61.8 & $100 \%$ & 65.5 & $100 \%$ & 72.6 & $100 \%$ & 74.7 & $100 \%$ & 75.8 & $100 \%$ & 77.2 & $100 \%$ \\
\hline $\begin{array}{c}\text { Cement }+ \\
\text { nano }(C N)\end{array}$ & 72.5 & $117 \%$ & 77.1 & $117 \%$ & 81.8 & $114 \%$ & 85.8 & $114 \%$ & 86.8 & $115 \%$ & 88.1 & $114 \%$ \\
\hline $\begin{array}{l}\text { Cement+silic } \\
\text { a (CS) }\end{array}$ & 81.4 & $131 \%$ & 94.6 & $144 \%$ & 86.3 & $118 \%$ & 96.5 & $129 \%$ & 95.9 & $126 \%$ & 97.8 & $126 \%$ \\
\hline $\begin{array}{l}\text { Cement+nano } \\
\text { +silica (CSN) }\end{array}$ & 80.5 & $130 \%$ & 93.2 & $142 \%$ & 84.4 & $117 \%$ & 95.6 & $127 \%$ & 93.9 & $123 \%$ & 96.2 & $124 \%$ \\
\hline
\end{tabular}

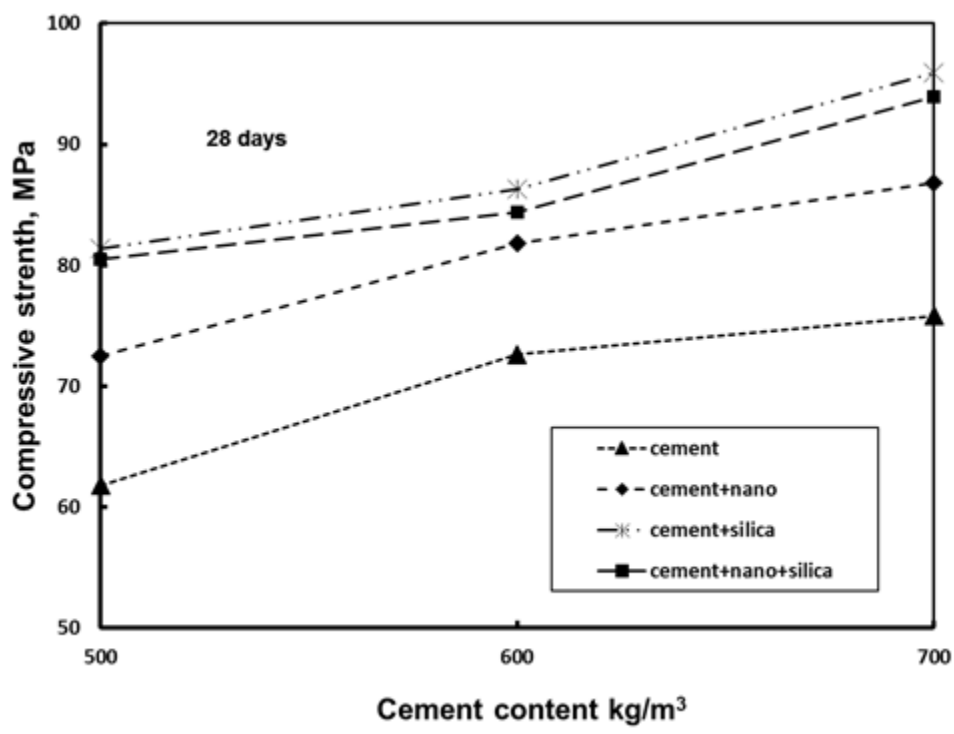

Figure (1): Compressive strength, $\sigma_{c}$, against cement content, cc, for different mixes at 28 days

A comparison between the results of the specimens containing Nano silica, silica fume and both Nano silica and silica fumes shows the following: specimens containing $1 \%$ Nano silica gave compressive strength results of about $85 \%$ of those of specimens containing $10 \%$ silica fume on the average. This reflects the effectiveness of the Nano silica, which is a result of its Nano size (average diameter $=19.4 \mathrm{~nm}$ ) compared to the size of the Mino silica. It can also be seen that specimens contains both $1 \%$ N.S. and $10 \%$ S.F. gave also results quite close to those of the $10 \%$ S.F. specimens. This may be attributed to the limited amount of free lime (calcium hydroxide) to react with both Nano silica and silica fume available in these specimens [6].

Fig. 2 shows the behavior of 56 days $\sigma_{c}$ against cement content for all mixes. From the data in this figure it's clear that the compressive strength of all mixes increases as the cement content increase from $500 \mathrm{~kg} / \mathrm{m}^{3}$ to $700 \mathrm{~kg} / \mathrm{m}^{3}$. The rate of increasing in compressive strength with cement content is approximately equals for cement and cement+ Nano mixes. While the mixes of cement + silica and cement $+\mathrm{Nano}+$ silica showed a lower rate of increasing from 500 to $700 \mathrm{~kg} / \mathrm{m}^{3}$. Moreover, the incorporating of silica fume in mix gives more benefit for compressive strength, where $\sigma_{\mathrm{c}}$ of cement + silica mix is higher than other mixes. 


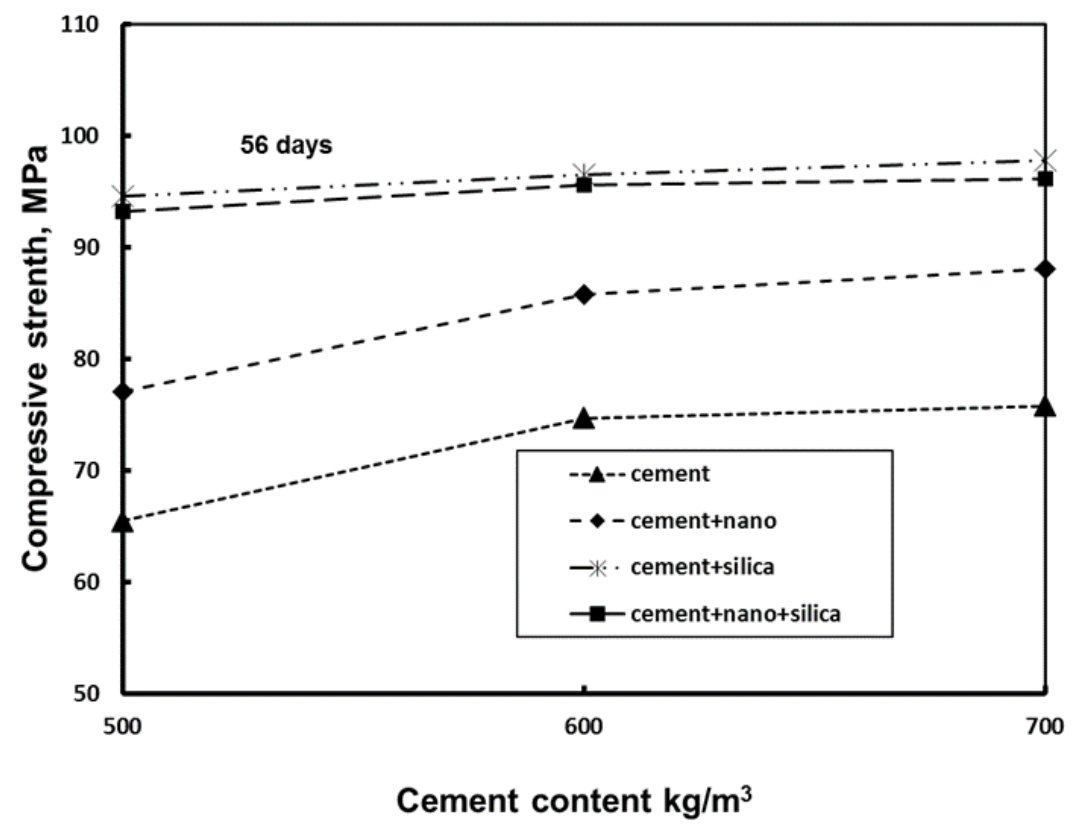

Figure (2) : Compressive strength, $\sigma_{c}$, against cement content, cc, for different mixes at 56 days

As shown from results, the presence of $1 \%$ Nano silica increase the compressive strength of the test specimen at 56 day by $17 \%, 14 \%$ and $17 \%$ for cement contents of 500, 600 and 700 $\mathrm{kg} / \mathrm{m}^{3}$ respectively. This can be related to the effect of pozzolanic reaction of the Nano silica material. The Nano silica with the free calcium hydroxide resulting from the hydration of cement compound, and the resulting compounds filled the inner pores leading to lower permeability and higher ability to resist lead (physical effect)[8]. In addition the resulting compounds are active due to Calcium Silicate hydrates, which are actually a cementation material increasing the ability to resist high load (chemical effect). A comparison between the results of the specimens containing Nano Silica, Silica fume and both Nano silica and Silica fumes shows the following: specimens containing 1\% Nano Silica fume gave compressive strength results of about $80 \%$ of those of specimens containing $10 \%$ Silica fume on the average. This reflects the effectiveness of the Nano Silica, which is a result of its Nano size (average diameter $=19.4 \mathrm{~nm}$ ) compared to the size of the Micro Silica, it can also be seen that specimens contain both $1 \%$ N.S, and $10 \%$ S.f gave also results quite close to those of the $10 \%$ S.f specimens. This may be attributed to the limited amount of the free lime (Calcium Hydroxide) to react with both Nano Silica and Silica fume available in these specimens [7] and $[8]$.

\section{B- Splitting Tensile Strength:}

Table (6) presents the experimental test results for the splitting tensile strength of concrete for the variation of cement content, namely, 500,600 and $700 \mathrm{~kg} / \mathrm{m}^{3}$ for mixes containing $10 \%$ silica fume (CS), mixes of $1 \%$ Nano silica $(\mathrm{CN})$ and combined $10 \%$ silica plus $1 \%$ Nano silica (CSN) tested at 28 and 56 days.

For discussing the splitting tensile strength $\sigma_{t}$ behavior at 28 days, figure (3) illustrates such behavior $\sigma_{t}$ versus cement content for mixes mentioned before. From this figure, it is clear that the splitting tensile strength. $\sigma_{t}$ increases as cement content increases for all mixes. By regarding to table (6) one can notices that for cement content of $700 \mathrm{~kg} / \mathrm{m}^{3}$, the highest tensile strength was for cement+silica+nano mix of $7.3 \mathrm{MPa}$ with relative increment of $110 \%$ with respect to the cement mix which is the control mix and the lowest tensile strength was for the cement+silica+nano mix of $7.1 \mathrm{MPa}$ with relative increment of $107 \%$ with respect to the control mix. The increase in tensile strength as cement content increase may be due to the increase of the free lime amount produced from cement hydration that produces more calcium silicate hydrates from pozzolanic reaction so more filling of concrete pores and so rising concrete strength. The highest strength was for cement+silica+nano mix due to the more use of free lime in pozzolanic reaction and the lowest for nano concrete may due to the less exploitation of the free lime amount for $1 \%$ nano silica. 
Table (6) Splitting tensile strength results

\begin{tabular}{|c|c|c|c|c|c|c|c|c|c|c|c|c|}
\hline \multirow[b]{3}{*}{ Mix } & \multicolumn{4}{|c|}{ C C $500 \mathrm{~kg} / \mathrm{m3}$} & \multicolumn{4}{|c|}{ C C $600 \mathrm{~kg} / \mathrm{m} 3$} & \multicolumn{4}{|c|}{ C C $700 \mathrm{~kg} / \mathrm{m3}$} \\
\hline & \multicolumn{2}{|c|}{28 day } & \multicolumn{2}{|c|}{56 day } & \multicolumn{2}{|c|}{28 day } & \multicolumn{2}{|c|}{56 day } & \multicolumn{2}{|c|}{28 day } & \multicolumn{2}{|c|}{56 day } \\
\hline & $\begin{array}{c}\sigma_{\mathrm{t}} \\
\mathrm{MPa}\end{array}$ & Relative & $\begin{array}{c}\sigma_{t} \\
\mathrm{MPa}\end{array}$ & Relative & $\begin{array}{c}\sigma_{\mathrm{t}} \\
\mathrm{MPa}\end{array}$ & Relative & $\begin{array}{c}\sigma_{t} \\
\mathrm{MPa}\end{array}$ & Relative & $\begin{array}{c}\sigma_{\mathrm{t}} \\
\mathrm{MPa}\end{array}$ & Relative & $\begin{array}{r}\sigma_{\mathrm{t}} \\
\mathrm{MPa}\end{array}$ & Relative \\
\hline Cement $(C)$ & 5.7 & $100 \%$ & 6 & $100 \%$ & 6.2 & $100 \%$ & 6.3 & $100 \%$ & 6.6 & $100 \%$ & 6.7 & $100 \%$ \\
\hline $\begin{array}{c}\text { Cement + } \\
\text { nano }(\mathrm{CN})\end{array}$ & 6.2 & $109 \%$ & 6.5 & $108 \%$ & 6.6 & $106 \%$ & 6.8 & $108 \%$ & 7.1 & $107 \%$ & 7.3 & $109 \%$ \\
\hline $\begin{array}{c}\text { Cement+sili } \\
\text { ca }(\mathrm{CS})\end{array}$ & 6.3 & $110 \%$ & 7 & $116 \%$ & 6.7 & $108 \%$ & 7.1 & $112 \%$ & 7.2 & $109 \%$ & 7.4 & $110 \%$ \\
\hline $\begin{array}{l}\text { Cement+nano } \\
+ \text { +silica, (CSN) }\end{array}$ & 6.4 & $112 \%$ & 7.3 & $121 \%$ & 6.8 & $110 \%$ & 7.2 & $114 \%$ & 7.3 & $110 \%$ & 7.5 & $111 \%$ \\
\hline
\end{tabular}

The effect of cement content on 56 days tensile strength was similar to that behavior at 28 days for all mixes as illustrated in figure (4). Also, cement+silica+nano mix shows the highest tensile strength and cement+nano mix shows the lowest tensile strength with respect to cement mix for all cement contents used. The highest strength for cement+silica+nano mix may be attributed to the full exploitation of free lime resulted from cement hydration in pozzolanic reaction process which has more active silica of combined nano+silica

Comparing the results of cement+nano mix, cement+silica mix and cement+ nano+ silica mix, it can be seen that mix contain $1 \%$ N.S, gave also results quite close to those of $10 \%$ S.f mix and also the combined mix of $1 \%$ N.S $+10 \%$ S.f. This shows the effectiveness of the Nano Silica, which is a result of its Nano size (average diameter $=19.4 \mathrm{~nm}$ ) compared to the size of the Micro Silica and also the limited amount of the free lime (Calcium Hydroxide) to react with both Nano Silica and Silica fume available in these mixes [6] and [16].

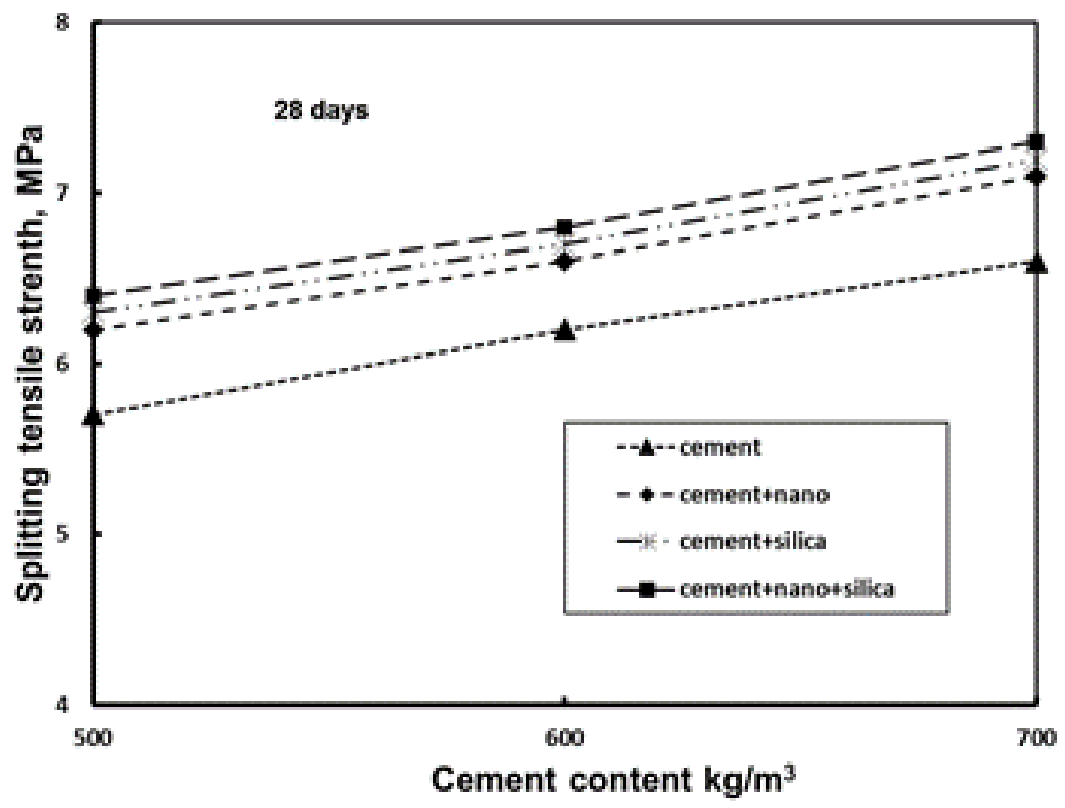

Figure (3): Splitting tensile strength, $\sigma_{t}$ versus cement content, cc, for different mixes at 28 days 


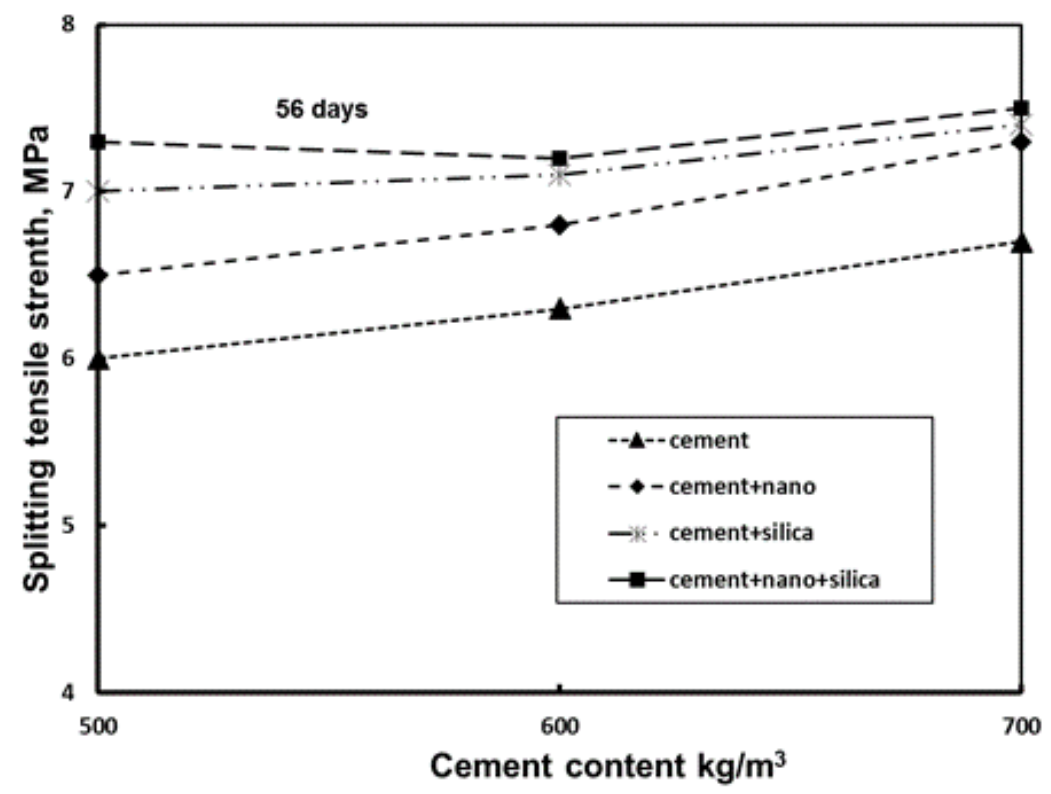

Figure (4): Splitting tensile strength, $\sigma_{t}$, versus cement content, cc, for different mixes at 56 days One further remark with regards to economy, although mix CN containers N.S gave strength results close to that of the mix C.S containing S.F, its cost is still high enough compared to that of the S.F. However, it is possible with the progress in research and development to have N.S. with lower cost.

\section{C- Relation between compressive and splitting tensile strengths:}

The ratio of tensile strength to compressive strength $\sigma_{t} / \sigma_{c} \%$, for mixes of the experimental program is calculated and listed in table (7). Figure (5) and Figure (6) present the ratio of tensile to compressive strength, $\sigma_{t} / \sigma_{\mathrm{c}}$ for all concrete mixes versus cement content for 28 days and 56 days respectively.

Table (7) Ratio between $\sigma_{\mathrm{t}}$ and $\sigma_{\mathrm{c}}$ as a percentage

\begin{tabular}{|c|c|c|c|c|c|c|}
\hline \multirow{2}{*}{ Mix } & \multicolumn{2}{|c|}{$\mathbf{C ~ C ~ 5 0 0 ~} \mathbf{~ k g} / \mathbf{m}^{3}$} & \multicolumn{2}{c|}{$\mathbf{C} \mathbf{C ~ 6 0 0 ~} \mathbf{~ k g} / \mathbf{m}^{3}$} & \multicolumn{2}{c|}{$\mathbf{C ~ C ~ 7 0 0 ~} \mathbf{~ k g} / \mathbf{m}^{3}$} \\
\cline { 2 - 7 } & 28 days & 56 days & 28 days & 56 days & 28 days & 56 days \\
\hline Cement $(\mathbf{C})$ & 9.22 & 9.10 & 8.54 & 8.43 & 8.70 & 8.60 \\
\hline Cement + nano (CN) & 8.54 & 8.43 & 8.06 & 7.93 & 8.10 & 8.29 \\
\hline Cement+silica (CS) & 7.74 & 7.40 & 7.76 & 7.31 & 7.51 & 7.57 \\
\hline Cement+nano+silica (CSN) & 7.95 & 7.83 & 8.05 & 7.74 & 7.70 & 7.70 \\
\hline
\end{tabular}

Generally there is a decrease in $\sigma_{t} / \sigma_{\mathrm{c}}$ as cement content increased at 28 days as reported by many investigators [15] and [16] since they stated that as the compressive strength of concrete increased, the tensile strength decreased and consequently there is a decrease in $\sigma_{t} / \sigma_{c}$ Also, there is a similar effect of cement content on $\sigma_{t} / \sigma_{c}$ ratio at 28days and at 56 days for cement mix , and cement+nano mix, cement+silica+nano mix as $\sigma_{t} / \sigma_{c}$ decreases from $500 \mathrm{~kg} / \mathrm{m}^{3}$ to $600 \mathrm{~kg} / \mathrm{m}^{3}$ then increased up to $700 \mathrm{~kg} / \mathrm{m}^{3}$ but this increase still less than that of $500 \mathrm{~kg} / \mathrm{m}^{3}$ by comparing fig (5) and fig (6). For the other two mixes, cement+silica, cement+silica+nano, there is steady behavior of $\sigma_{t} / \sigma_{c}$ at 28 days and at 56 days for cement content range from $500 \mathrm{~kg} / \mathrm{m}^{3}$ to $600 \mathrm{~kg} / \mathrm{m}^{3}$ but from $600 \mathrm{~kg} / \mathrm{m}^{3}$ to $700 \mathrm{~kg} / \mathrm{m}^{3}$ the behavior is completely different from 28 days behavior to that of 56days for the same two mixes.

Comparing the test results of compressive strength with those of the tensile strength, it is implied that the increase in the strength due to the presence of N.S., S.F. or both N.S. and S.F. was low in the case of tension than in the case of compression. This may be explained that the role of the pozzolanic materials in increasing the strength of the test concrete specimen is low in case of tension than in the case of compression. The physical effect of pozzolanic material (filling the inner pores) has a smaller role in the case of tension. 
One notices can be taken into consideration is the cost calculation for the mixes of experimental program since the cost of $10 \%$ silica fume mix is lower than that of $1 \%$ Nano silica mix but the strength gained from the $1 \%$ Nano silica mix is still approximately closed to $10 \%$ silica fume mix.

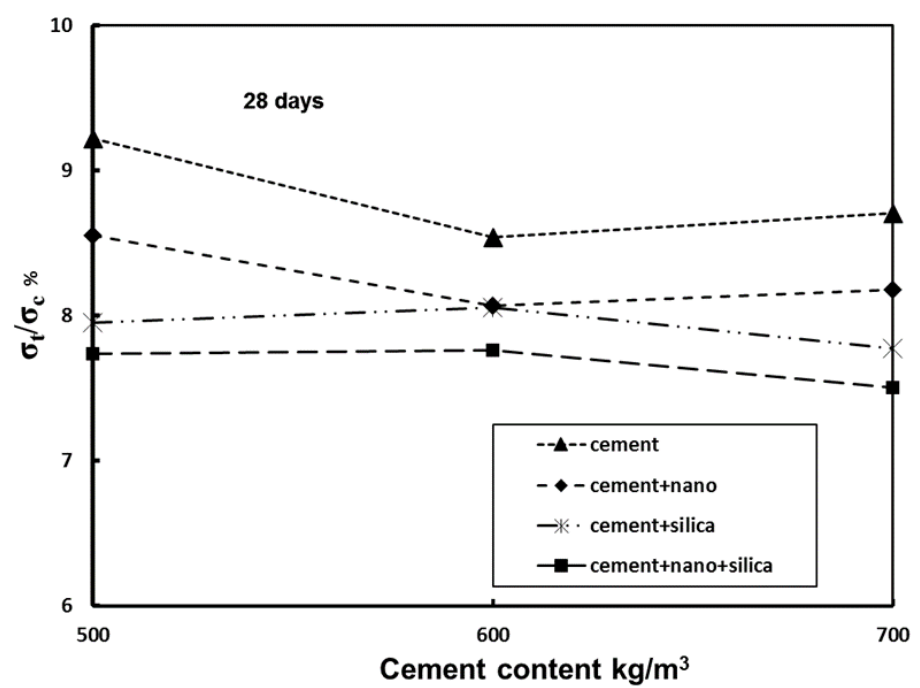

Figure (5): $\sigma_{\mathrm{t}} / \sigma_{\mathrm{c} \%}$ versus cement content, cc, for different mixes at 28 days

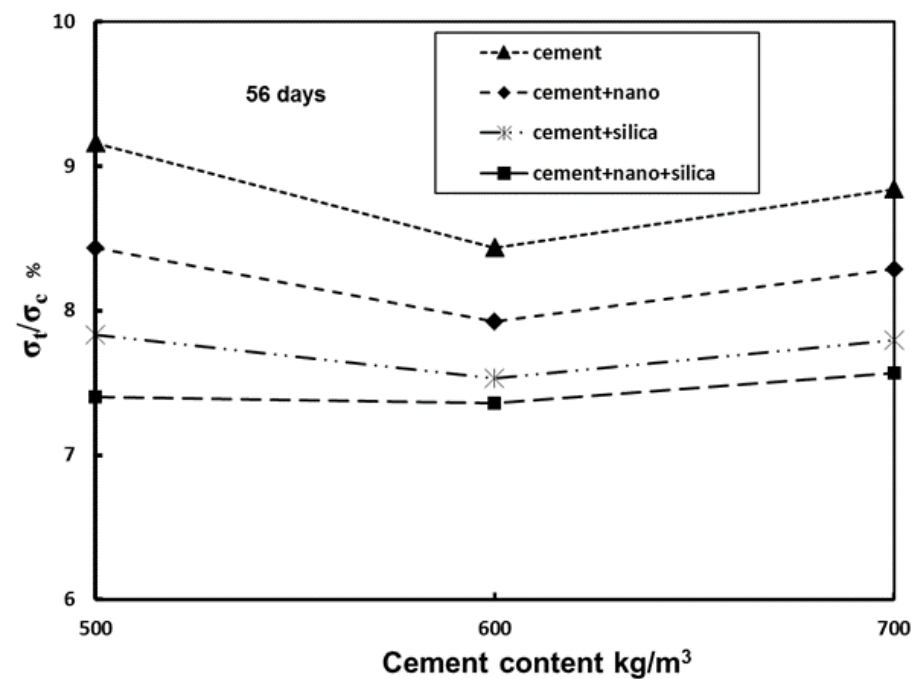

Figure (6): $\sigma_{t} / \sigma_{\mathrm{c}} \%$ versus cement content, cc, for different mixes at 56 days

\section{CONCLUSIONS:}

Within the scope of this study the following conclusions can be shown:

1. The compressive strength of concrete mixes with and without pozzolanic admixtures increased as the cement content increased from 500 to $700 \mathrm{~kg} / \mathrm{m}^{3}$.

2. The increase in the compressive strength at 56 days was higher in case of mixes with pozzolanic admixtures than in the reference mix as compared to the strength at 28 days.

3. The concrete mix with $1 \%$ nano silica gave almost $90 \%$ of the compressive strength of the concrete mix with $10 \%$ silica fume as a result of its nano size.

4. The concrete mix with $1 \%$ nano silica and $10 \%$ silica fume gave almost the same compressive strength of the mix with $10 \%$ silica fume, which may be attributed to the limited amount of free lime to react with both of them. 
5. Results of the splitting tensile strength showed the same trend of results of the compressive strength test for the different concrete mixes.

6. The ratio of the splitting tensile to compressive strength was about $9 \%$ for the reference concrete mix at 28 and 56 days for the different cement contents. About 8 to $9 \%$ ratio was obtained for the other mixes containing nano silica and silica fume.

\section{REFERENCES}

1. Anderson D., Roy A., Seals R.K., Cartledge F.K., Akhter H., Jones S.C., Apreliminary assessment of the use of an amorphous silica residual as asupplementary cementing material, Cement and Concrete Research, 2000, 30,437-445.

2. Susheel S M, Sanyith J and Ranjith A, Effect of nano silica fume on concrete, IJISETInternational Journal of Innovative Science, Engineering \& Technology, Vol. 3 Issue 6, June 2016.

3. Qing Y., Zenan Z., Deyu K., Rong S.C., Influence of nano-SiO2 addition onproperties of hardened cement paste as compared with silica fume,Construction and Building Materials 2007, 21, 539-545.

4. LI H., Zhang M.H., OU J.P., Abrasion resistance of concrete containing nanoparticles for pavement, Wear, 2006,260, 1262-1266.

5. Lin K.L., Chang W.C., Lin D.F., Luo H.L, Tsai M.C., Effects of nano-SiO2and different ash particle sizes on sludge ash-cement mortar, Journal of Environmental Management doi:10.1016./j.jenvman.2007.03.036( 2007).

6. IS: 456-2000, "Pla in and reinforced concrete code for practice", Bureau of Indian Standards, New Delhi.8. Rao G.A., Investigations on the performance of silica fumeincorporated cement pastes and mortars, Cement and Concrete Research, 2003, 33, 1765 1770.

7. Isaia G.C., Gastaldini A.L.G., Moraes R., Physical and pozzolanic action ofmineral addition on the mechanical strength of high-performance concrete, Cement and Concrete Research, 2003, 25, 69-76.

8. Zelic J., Rusic D., Veza D., Krstulovic R., The role of silica fume in the kinetics and mechanisms during the early stage of cement hydration, Cement and Concrete Research, 2000, 30, 1655-1662.

9. RAO G.A., Long-term drying shrinkage of mortar-influence of silica fume an dsize of fine aggregate, Cement and Concrete Research, 2001, 31, 171-175.12. RAO G.A., Influence of silica fume replacement of cement on expansion and drying shrinkage, Cement and Concrete Research, 1998, 28, 1505-1509.

10. Paramita Mondal, Surendra P. Shah, Laurence D. Marks, and Juan J. Gaitero Comparative Studies On High Strength Concrete Mixes Us ing Micro Silica And NanoSilica", Internationa 1 Journal of Engineering a nd Technica 1 Research(IJETR) ISSN: 2321-0869, Volume-1, Issue-7, September 2013.

11. An Overview on the Influence of Nano-Silica in Concrete and a Research Initiative", Research Journal of Recent Sciences ISSN 2277-2502 Vol. 2(ISC-2012), 17-24 (2013) Res. J. Recent. Sci. International.

12. IS: 516-1991, "Methods of tests for strength of concrete", Bureau of Indian Standards, New Delhi.16.

13. IS: 10262-2009, "Concrete Mix Proportioning-Guide lines", Bureau of Indian Standards, New Delhi.

14. Quing, research on the comparison of the pozzolanic activity between Nano SiO2 and Silica fume concrete, 2001,3,19_22

15. Mutiu A. Akinpelu a , Samson O. Odeyemi a , Oladipupo S. Olafusi b, , Fatimah Z. Muhammed " Evaluation of splitting tensile and compressive strength relationship of self-compacting concrete" Journal of King Saud University - Engineering Sciences, January, 2017

16. N. Anglu, Z.C. Girgin, E.Anoglu "Evaluation of ratio between splitting tensile strength and compressive strength for concretes up to $120 \mathrm{MPa}$ and its application in strength criterion" , ACI Mater. J., 103 (1) (2006), pp. 18-24 